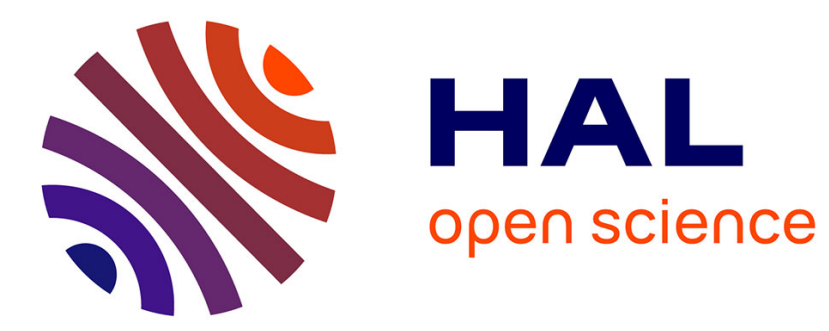

\title{
Temperature-based model for monthly average hourly global solar radiation for the Caribbean island of Trinidad
}

Keith de Souza

\section{> To cite this version:}

Keith de Souza. Temperature-based model for monthly average hourly global solar radiation for the Caribbean island of Trinidad. Journal of Renewable and Sustainable Energy, 2018, 10 (3), pp.033701. 10.1063/1.5000817. halshs-02133809

\section{HAL Id: halshs-02133809 \\ https://shs.hal.science/halshs-02133809}

Submitted on 20 May 2019

HAL is a multi-disciplinary open access archive for the deposit and dissemination of scientific research documents, whether they are published or not. The documents may come from teaching and research institutions in France or abroad, or from public or private research centers.
L'archive ouverte pluridisciplinaire HAL, est destinée au dépôt et à la diffusion de documents scientifiques de niveau recherche, publiés ou non, émanant des établissements d'enseignement et de recherche français ou étrangers, des laboratoires publics ou privés. 
Temperature-based model for monthly average hourly global solar radiation for the Caribbean island of Trinidad

Keith De Souza

Citation: Journal of Renewable and Sustainable Energy 10, 033701 (2018); doi: 10.1063/1.5000817

View online: https://doi.org/10.1063/1.5000817

View Table of Contents: http://aip.scitation.org/toc/rse/10/3

Published by the American Institute of Physics 


\title{
Temperature-based model for monthly average hourly global solar radiation for the Caribbean island of Trinidad
}

\author{
Keith De Souza \\ Center for Optoelectronics Research, Diego Martin, Trinidad and Tobago
}

(Received 18 August 2017; accepted 5 May 2018; published online 24 May 2018)

Hourly global solar radiation data are required to optimize various solar energy based designs. In this study, a new empirical temperature-based model for determining monthly average hourly global solar radiation on a horizontal surface for the Caribbean island of Trinidad was developed and validated using calibration and validation datasets of hourly global solar radiation and temperature from 2001 to 2005 and 2006 to 2010, respectively. The new model was evaluated alongside five existing monthly average hourly radiation ratio models due to Whillier/Liu and Jordan, Collares-Pereira and Rabl, Gueymard, Newell, and Jain. For all six models, measured and calculated monthly average hourly global solar radiation over the five-year validation period 2006-2010 were compared statistically using mean bias error, root mean square error, correlation coefficient, and Nash-Sutcliffe efficiency. For an average year, the temperature-based model was the best performing model for two months, the Collares-Pereira and Rabl and Gueymard models for ten months, and the Whillier/Liu and Jordan model for one month. Over an average year, the temperature-based and Gueymard models yielded root mean square errors of $0.12 \mathrm{MJ} \mathrm{m}^{-2} \mathrm{~h}^{-1}$ and $0.10 \mathrm{MJ} \mathrm{m}^{-2} \mathrm{~h}^{-1}$, respectively. Over the single years from 2006 to 2010, the models were evaluated for performance and robustness toward inter-annual fluctuations in global solar radiation and temperature. Some redistribution of the same four models occurred among the months over the years, but overall, they were in agreement with those obtained for an average year. The Newell model was the most robust. Over these five years, the temperature-based and Gueymard models yielded root mean square errors of $0.17 \mathrm{MJ} \mathrm{m}^{-2} \mathrm{~h}^{-1}$ and $0.14 \mathrm{MJ}$ $\mathrm{m}^{-2} \mathrm{~h}^{-1}$, respectively. For modeling of monthly average hourly global solar radiation on both yearly and average year bases, the temperature-based and Gueymard models were most suitable with root mean square errors of $0.15 \mathrm{MJ} \mathrm{m}^{-2} \mathrm{~h}^{-1}$ and $0.12 \mathrm{MJ} \mathrm{m}^{-2} \mathrm{~h}^{-1}$, respectively. Advantageously, the temperature-based model is independent of global solar radiation input unlike the other models. Published by AIP Publishing. https://doi.org/10.1063/1.5000817

\section{INTRODUCTION}

The Caribbean island of Trinidad, located just off the northeast coast of Venezuela at $10^{\circ} 35^{\prime} \mathrm{N}$ latitude and $61^{\circ} 21^{\prime} \mathrm{W}$ longitude, has an area of $4827 \mathrm{~km}^{2}$ and two seasonal climates called the Tropical Maritime or dry season and the Modified Moist Equatorial or wet season. These seasons occur from January to May and June to December, respectively. Trinidad has an average minimum and maximum temperature of $22.7^{\circ} \mathrm{C}$ and $31.3^{\circ} \mathrm{C}$, respectively, and a mean annual rainfall from a minimum of $1500 \mathrm{~mm}$ to a maximum of $3500 \mathrm{~mm}$.

Trinidad is the leading producer and exporter of oil and natural gas in the Caribbean but like most countries is on a drive to implement alternative sources of energy to achieve energy security while reducing the country's carbon footprint and effects of global warming. Solar energy is undoubtedly and indisputably the most viable source of renewable energy implementable in Trinidad, and resources should be channeled towards this cause. The average daily global solar radiation, total global solar radiation, average daily number of sunshine hours, and 
average total number of sunshine hours have previously been calculated to be ${ }^{1} 16.93 \pm 0.73$ $\mathrm{MJm}^{-2}$ day $^{-1}, 2.56 \pm 0.11 \mathrm{GJm}^{-2}, 8.49 \pm 0.44 \mathrm{~h} \mathrm{day}^{-1}$, and $1282 \pm 67 \mathrm{~h}$, respectively, for the dry season, $15.52 \pm 0.81 \mathrm{MJm}^{-2} \mathrm{day}^{-1}, 3.32 \pm 0.17 \mathrm{GJm}^{-2}, 7.03 \pm 0.38 \mathrm{~h} \mathrm{day}^{-1}$, and $1504 \pm 81$ $\mathrm{h}$, respectively, for the wet season, and $16.08 \pm 0.71 \mathrm{MJm}^{-2} \mathrm{day}^{-1}, 5.87 \pm 0.26 \mathrm{GJm}^{-2}$, $7.65 \pm 0.24 \mathrm{~h} \mathrm{day}^{-1}$, and $2792 \pm 83 \mathrm{~h}$, respectively, for the whole year.

While daily global solar radiation data are important in many applications and research areas such as photovoltaic system (PV) design, ${ }^{2}$ building design, ${ }^{3}$ thermal comfort studies, ${ }^{4}$ solar thermal system design, ${ }^{5}$ crop growth models,${ }^{6}$ evapotranspiration, ${ }^{7}$ and hybrid solar-wind systems, ${ }^{8}$ hourly global solar radiation data allow greater accuracy in modeling, analyzing, and designing such solar energy applications and systems. Average hourly/daily global solar radiation ratios on a horizontal surface have been modeled theoretically by many researchers over the years, and some of these models ${ }^{9-14}$ have been applied to different parts of the world. These models require measured monthly average daily global solar radiation to calculate monthly average hourly global solar radiation. Empirical modeling of hourly global solar radiation has been done in terms of meteorological parameters only or along with additional inputs. Some of these models require daily precipitation and minimum and maximum air temperatures ${ }^{15}$ mean daily global solar radiation, hour angle, and sunset hour angle using a regression artificial neural network; ${ }^{16}$ combined ambient temperature and relative humidity using a decision matrix of atmospheric transmittance or relative humidity, clearness index, and beam atmospheric transmission; ${ }^{17}$ peak sunshine hours, day length, and latitude; ${ }^{18}$ daily global solar radiation; ${ }^{19}$ and satellite data, temperature, humidity, and aerosols. ${ }^{20}$ None of these models utilize ambient temperature as the sole meteorological variable. There are models that require temperature as the sole meteorological variable, but such models are not used to estimate hourly global solar radiation but daily averages of global solar radiation. Moreover, they also require the additional input of daily extraterrestrial global solar radiation and in some cases geographical factors. Some examples of such models are due to Hargreaves and Samani ${ }^{21}$ which uses the difference in daily maximum and minimum temperatures and a single calibration coefficient; Bristow and Campbell ${ }^{22}$ based on the difference in maximum and minimum temperatures and three empirical coefficients; Annandale et al. ${ }^{23}$ with a modified Hargreaves-Samani model having an altitude-dependent factor; Allen ${ }^{24}$ with a self-calibrating model based on Hargreaves and Samani's model and Goodin et al. ${ }^{25}$ who modified Bristow and Campbell's model by introducing daily extra-terrestrial global solar radiation in the model to act as a seasonal scaling factor.

In this paper, a new empirical model that calculates monthly average hourly global solar radiation on a horizontal surface based on only one input, ambient hourly temperature, is developed and evaluated using data over the period 2001-2010. Calibration and validation datasets from 2001 to 2005 and 2006 to 2010, respectively, were used to develop and evaluate the model. The data were obtained from the Trinidad and Tobago Meteorological Service, located at $10^{\circ} 35^{\prime} \mathrm{N}$ latitude, $61^{\circ} 21^{\prime} \mathrm{W}$ longitude, and $21.95 \mathrm{~m}$ above mean sea level. In addition, a comprehensive study to evaluate five theoretical hourly global solar radiation ratio models was undertaken. The models selected were those developed by Whillier/Liu and Jordan (WLJ), ${ }^{9,10}$ Collares-Pereira and Rabl (CPR),${ }^{11}$ Gueymard (CPRG), ${ }^{12}$ Newell $(\mathrm{N}),{ }^{13}$ and Jain (J). ${ }^{14}$ These models are semi-empirical in application since they all require measured monthly average daily global solar radiation as an input to calculate monthly average hourly global solar radiation.

The main motivation for this work was to develop an empirical model that satisfactorily predicts monthly average hourly global solar radiation on a horizontal surface based on the single meteorological input of hourly temperature and hence no dependence on solar radiation. The objectives of this paper are (i) to formulate the new empirically derived model based on temperature only, (ii) to comprehensively evaluate and compare all six models-the empirical and five theoretical, for applicability in Trinidad over an average year using the five-year validation dataset, (iii) to comprehensively evaluate the performance of the models over single years within the validation dataset, and (iv) to propose the most suitable model or models for monthly and yearly application. Evaluation and comparisons were done graphically and statistically by comparing calculated and measured monthly average hourly global solar radiation 
using four statistical test parameters, namely, mean bias error $(M B E)$, root mean square error (RMSE), correlation coefficient ( $r$ ), and Nash-Sutcliffe efficiency (NSE).

This study will contribute significantly to Trinidad, the islands of the Caribbean and geographical regions with a similar climate and more so in such locations where hourly global solar radiation is not available. The study will allow solar energy conversion systems and applications to be designed and implemented more accurately, efficiently, and economically in Trinidad. In addition, energy-efficient building designs can be developed that optimize human thermal comfort, thereby mitigating against sick-building syndrome. In the sphere of agriculture, where there is a thrust towards achieving food-security and self-sufficiency, this study can be used in crop growth models to predict and optimize crop yields as well as in thermal comfort studies for livestock productivity. These applications, if implemented, would reduce Trinidad's fossil fuel dependence and carbon footprint.

This paper is organized as follows. Section II provides the theory of the six hourly models under consideration and the statistical test parameters. Section III describes the methodology, and Sec. IV presents the results and discussion. Conclusions are given in Sec. V.

\section{THEORY}

The WLJ, CPR, CPRG, N, and J models were developed for a wide range of climates, and this study would determine whether they are weighted for or against the tropical climate of Trinidad. These models and the new empirical temperature-based model used for calculating monthly average hourly global solar radiation are presented in Subsections II A-II F in the following order: Whillier/Liu and Jordan (WLJ), Collares-Pereira and Rabl (CPR), Gueymard $(\mathrm{CPRG})$, Newell $(\mathrm{N})$, Jain $(\mathrm{J})$, and the new model which for consistency and ease of reference will be referred to as the De Souza (D) model. Subsection II G provides well-established equations to convert local standard time to local solar time. Subsection II H addresses the statistical test parameters used to evaluate the performance of the models.

\section{A. The Whillier/Liu and Jordan model (WLJ)}

In this model, ${ }^{9,10}$ the extraterrestrial hourly/daily global solar radiation ratio is defined as

$$
r_{-} W L J=\frac{\pi}{24} \frac{\left(\cos \omega_{h}-\cos \omega_{s}\right)}{\left(\sin \omega_{s}-\omega_{s} \cos \omega_{s}\right)},
$$

where $\omega_{s}$ and $\omega_{h}$ are the sunset hour angle and solar hour angle, respectively, in radians. The following equation $\left(\operatorname{Sen}^{26}\right)$ defines $\omega_{s}$ as

$$
\omega_{s}=\cos ^{-1}(-\tan \varphi \tan \delta),
$$

where $\varphi$ is the latitude of the location in degrees and the astronomical parameter, $\delta$, is the sun declination angle defined as ${ }^{27}$

$$
\delta=23.45 \sin \left[360 \frac{(284+x)}{365}\right], \quad-23.45^{\circ} \leq \delta \leq 23.45^{\circ}
$$

where $x$ is the day of the year; for example, January 1 st means that $x=1$. The solar hour angle, $\omega_{h}$, is the angle of the sun, east or west of the local line of longitude due to rotation of the earth on its axis at $15^{\circ}$ per hour. It is defined as

$$
\omega_{h}=\frac{\pi}{180}\left[\frac{360}{24}\left(t_{S O L}-12\right)\right]=\frac{\pi}{12}\left(t_{S O L}-12\right),
$$

where $t_{S O L}$ is the local solar time at the midpoint of the hourly period of interest. It should be noted that $\omega_{h}$ is zero at solar noon, negative before solar noon, and positive after solar noon in the northern hemisphere. The signs are reversed in the southern hemisphere. 


\section{B. The Collares-Pereira and Rabl model (CPR)}

The CPR model ${ }^{11}$ modifies WLJ's model to take into account effects due to the atmosphere. The radiation ratio, $r_{-} C P R$, is given by

$$
r_{-} C P R=\left(a+b \cos \omega_{h}\right) r_{-} W L J
$$

where

$$
\begin{aligned}
& a=0.409+0.5016 \sin \left(\omega_{s}-1.047\right) \\
& \text { and } \quad b=0.6609-0.4767 \sin \left(\omega_{s}-1.047\right) \text {. }
\end{aligned}
$$

\section{The Gueymard model (CPRG)}

The CPRG model ${ }^{12}$ renormalizes the CPR model yielding the radiation ratio, $r_{-} C P R G$, given by

$$
r_{-} C P R G=\frac{r_{-} C P R}{f\left(\omega_{s}\right)}
$$

where

$$
f\left(\omega_{s}\right)=a+\frac{0.5 b\left(\omega_{s}-\sin \omega_{s} \cos \omega_{s}\right)}{\sin \omega_{s}-\omega_{s} \cos \omega_{s}}
$$

and $a$ and $b$ have been defined in Eqs. (6) and (7).

\section{The Newell model (N)}

The $\mathrm{N}$ mode ${ }^{13}$ is a parabolic model with radiation ratio, $r_{-} N$, given by

$$
r N=\frac{1.5}{S_{o}}\left[1-4\left(\frac{t_{S O L}-12}{S_{o}}\right)^{2}\right],
$$

where the day length in hours, $S_{o}$, is defined as

$$
S_{o}=\frac{24}{\pi} \omega_{s}
$$

Substituting Eq. (11) into Eq. (10) gives the expression

$$
r_{-} N=\frac{1.5 \pi}{24 \omega_{s}}\left[1-\left(\frac{\omega_{h}}{\omega_{s}}\right)^{2}\right],
$$

where $\omega_{s}$ and $\omega_{h}$ are defined in Eqs. (2) and (4), respectively.

\section{E. The Jain model ( $\mathrm{J})$}

The $\mathrm{J}$ model, ${ }^{14}$ based on a Gaussian or normal distribution, yields a radiation ratio, $r_{-} J$, given by

$$
r_{\lrcorner} J=\frac{1}{\sigma \sqrt{2 \pi}} \exp \left[-\frac{1}{2}\left(\frac{t_{S O L}-12}{\sigma}\right)^{2}\right],
$$

where 


$$
\sigma=0.461+0.192 S_{o}
$$

$S_{o}$ is defined in Eq. (11). From Eq. (4), Eq. (13) can be expressed as

$$
r_{\lrcorner} J=\frac{1}{\sigma \sqrt{2 \pi}} \exp \left[-\frac{1}{2}\left(\frac{12 \omega_{h}}{\pi \sigma}\right)^{2}\right]
$$

thereby expressing the model in terms of the solar hour angle $\omega_{h}$, as has been done for the previous five models.

For any of the aforementioned models, if the monthly average hourly radiation ratios, $\bar{r}$, and the measured monthly average daily radiation, $\bar{H}_{d}$, are computed, then the monthly average hourly radiation, $\bar{H}_{h}$, can be calculated using

$$
\bar{H}_{h}=\bar{r} \bar{H}_{d}
$$

\section{F. The new model-De Souza model (D)}

This monthly average hourly global solar radiation model distinguishes itself from the aforementioned models in being an empirically derived model. The D model for a typical day of any month is described by a pair of linear equations applicable to the day's morning and afternoon periods, respectively, and is given by

$$
\bar{H}_{m}=a \bar{T}_{m+1}-b
$$

and

$$
\bar{H}_{p}=c \bar{T}_{p+3}-d
$$

where $\bar{H}$ is the measured monthly average hourly global solar radiation, $\bar{T}$ is the measured monthly average hourly normalized temperature, i.e., measured monthly average hourly temperatures normalized to their corresponding monthly average daily $(24 \mathrm{~h}$ ) temperature, $m=6$, $7, \ldots ., 11$, where $\mathrm{m}$ refers to morning hours $6 \mathrm{~h}-11 \mathrm{~h}$ local standard time, $p=12,13, \ldots \ldots 17$, where $\mathrm{p}$ refers to afternoon hours $12 \mathrm{~h}-17 \mathrm{~h}$ local standard time, and $a, b, c$, and $d$ are the regression coefficients.

Unlike the theoretical models, the D model, after calibration, requires no global solar radiation data as an input but only hourly temperature data to calculate monthly average hourly global solar radiation.

\section{G. Conversion of local standard time to local solar time}

The Trinidad and Tobago Meteorological Services of Trinidad and Tobago records meteorological data in local standard time. The theoretical models covered in Subsections II A-IIE are defined in terms of solar time. In this work, local standard time has been converted to local solar time. Trinidad does not observe daylight saving time.

To convert local standard time, $t_{S T}$, to local solar time, $t_{S O L}$, use is made of ${ }^{28}$ Eqs. (19)-(21)

$$
t_{S O L}=t_{S T}+4\left(L_{S T}-L_{L O C}\right)+E O T
$$

where $L_{S T}$ is the standard meridian of the local time zone, $L_{L O C}$ is the longitude of the location of the weather station at which measurements were conducted (both longitudes are measured in degrees west), and EOT is the equation of time, in minutes, given by ${ }^{29}$ 
$E O T=229.2(0.000075+0.001868 \cos B-0.032077 \sin B-0.014615 \cos 2 B-0.04089 \sin 2 B)$,

where $B$, the day angle in degrees, is given by

$$
B=\frac{360(x-1)}{365}
$$

where $x$ is the day of the year. For example, $x=1$ corresponds to January 1 st. For this study, $L_{S T}=60^{\circ} \mathrm{W}$ and $L_{L O C}=61.35^{\circ} \mathrm{W}$.

\section{H. Statistical test parameters to evaluate and compare the models}

To determine how well measured and calculated monthly average hourly global solar radiation values agree with each other, four statistical test parameters are considered in this analysis. These include MBE $\left(\mathrm{MJ} \mathrm{m}^{-2} \mathrm{~h}^{-1}\right), \operatorname{RMSE}\left(\mathrm{MJ} \mathrm{m}^{-2} \mathrm{~h}^{-1}\right), r$, and NSE.

The following variables and statistical test parameters are defined as

$\bar{H}_{i, \text { calc }}=i$ th calculated value of monthly average hourly global solar radiation,

$\bar{H}_{i, \text { meas }}=i$ th measured value of monthly average hourly global solar radiation,

$n=$ no. of values of $\left(\bar{H}_{i, \text { calc }}, \bar{H}_{i, \text { meas }}\right)$,

$i=1, \ldots, n$,

$\bar{H}_{\text {calc }}=$ average of $\bar{H}_{i, c a l c}$,

$\bar{H}_{\text {meas }}=$ average of $\bar{H}_{i, \text { meas }}$.

$$
\begin{aligned}
& M B E=\frac{1}{n} \sum_{i=1}^{n}\left(\bar{H}_{i, \text { calc }}-\bar{H}_{i, \text { meas }}\right), \\
& R M S E=\left[\frac{1}{n} \sum_{i=1}^{n}\left(\bar{H}_{i, \text { calc }}-\bar{H}_{i, \text { meas }}\right)^{2}\right]^{1 / 2}, \\
& r=\frac{\sum_{\mathrm{i}=1}^{\mathrm{n}}\left(\bar{H}_{i, \text { meas }}-\bar{H}_{\text {meas }}\right)\left(\bar{H}_{i, \text { calc }}-\bar{H}_{\text {calc }}\right)}{\sqrt{\sum_{\mathrm{i}=1}^{\mathrm{n}}\left(\bar{H}_{i, \text { meas }}-\bar{H}_{\text {meas }}\right)^{2}} \sqrt{\sum_{\mathrm{i}=1}^{\mathrm{n}}\left(\bar{H}_{i, \text { calc }}-\bar{H}_{\text {calc }}\right)^{2}}}, \\
& N S E=1-\frac{\sum_{i=1}^{n}\left(\bar{H}_{i, \text { calc }}-\bar{H}_{i, \text { meas }}\right)^{2}}{\sum_{i=1}^{n}\left(\bar{H}_{i, \text { meas }}-\bar{H}_{\text {meas }}\right)^{2}}=1-\frac{n R M S E^{2}}{\sum_{i=1}^{n}\left(\bar{H}_{i, \text { meas }}-\bar{H}_{\text {meas }}\right)^{2}} \text {. }
\end{aligned}
$$

For better agreement between calculated and measured values, $M B E$ and RMSE lie closer to zero while for greater correlation, $r$ is closer to 1 . The $M B E$ is a measure of the long-term accuracy of the model and has an ideal value of 0 , when calculated values match measured values perfectly. For $M B E>0$ or $M B E<0$, on average, calculated values are overestimated or underestimated, respectively. An $M B E$ close to 0 can mean that the calculated values are very good estimates of the measured values. By its definition however, some caution must be observed from an $M B E$ result since the possibility exists that even if calculated and measured values may not agree very closely, the sum of the positive deviations can be almost nullified by the sum of the negative deviations yielding a very low $M B E$ that can misleadingly be interpreted as excellent model performance.

$R M S E$ is a measure of the short-term accuracy of the model. $R M S E \geq 0$ and has an ideal value of 0 for perfectly matched calculated and measured values. It gives a good measure of 
the accuracy of the calculated values. The squared deviation between calculated and measured values ameliorates the limitation of the $M B E$, but any large deviation between one or a few calculated-measured value pairs can lead to a significant increase in the RMSE value.

The correlation coefficient $r$ is a statistical measure of how calculated and measured values vary in relation to each other and is defined as the ratio of the covariance to the product of the standard deviations of the measured and calculated values and ranges over $-1 \leq r \leq 1$. Greater correlation and anti-correlation between calculated and measured values occur for $r$ closer to 1 and $r$ closer to -1 , respectively.

The NSE is defined as one minus the sum of the squared differences between the calculated and measured values normalized by the variance of the measured values and ranges over $-\infty \leq N S E \leq 1$. For $N S E<0$, the mean of the measured data is a better predictor than the model; for $N S E=0$, the mean of the measured data is as good a predictor as the model; for $N S E>0$, the model is the better predictor and ideally for $N S E=1$, the model's predictions match the measured data perfectly.

\section{METHODOLOGY}

Data of measured hourly global solar radiation were obtained from the Trinidad and Tobago Meteorological Services which is located at $10^{\circ} 35^{\prime} \mathrm{N}$ latitude, $61^{\circ} 21^{\prime} \mathrm{W}$ longitude, and $21.95 \mathrm{~m}$ above mean sea level. A digital Eppley Black and White pyranometer, S/N $28370 \mathrm{~F} 3$, having a specified hourly average uncertainty of $3 \%$ and a daily average uncertainty of $2 \%$, was used to measure hourly global solar radiation. An Eppley integrator, S/N 412-10076, was used to log the global solar radiation data. Temperatures were measured using dry bulb, wet bulb, maximum, and minimum thermometers located in a Stevenson screen $1.2 \mathrm{~m}$ $-2 \mathrm{~m}$ above ground. The dry bulb, wet bulb, and maximum thermometers were mercury in glass double sheathed, while the minimum thermometer was alcohol in glass, all made by Cassella UK Ltd., and conforming to British Standard 692. The measurement uncertainty of the thermometers was $\pm 0.05^{\circ} \mathrm{C}$. Temperatures were manually recorded every hour. The Trinidad and Tobago Meteorological Services, as a member of the World Meteorological Organization, follows the organization's standards and best practices with respect to maintenance and calibration of its instruments.

The hourly global solar radiation data were subjected to quality control to determine whether there were any days where global solar radiation exceeded theoretically calculated extraterrestrial solar radiation, which would have indicated erroneous data. None were found. The total number of measured hourly global solar radiation data points available from the ten-year dataset 2001-2010 from $6 \mathrm{~h}$ to $17 \mathrm{~h}$ was 39788 . The total number of data points for a complete dataset would have been 43800 . Thus, the total number of missing data points was 4012.

The full ten-year dataset 2001-2010 was used to develop graphs to show the hourly variation of global solar radiation and temperature as well as to show the monthly variation of temperature.

The ten-year dataset was then divided into a calibration dataset 2001-2005 and a validation dataset 2006-2010. For the calibration dataset, the total number of measured hourly global solar radiation data points was 21010 , and the corresponding number of data points for the validation dataset was 18778 . Similar calibration and validation datasets of hourly temperature were constructed. There were no missing hourly temperature data.

Subsection III A briefly addresses the conversion of local standard time to local solar time. Subsection III B describes the procedure for computing the hourly variation of global solar radiation and temperature and the monthly variation of temperature. Subsection IIIC describes the determination of the monthly average hourly global solar radiation for the WLJ, CPR, CPRG, $\mathrm{N}$, and J models. For the development of the D model, Subsection III D establishes the correlation between monthly average hourly global solar radiation and monthly average hourly normalized temperature and Subsection IIIE determines the D model. Evaluation and comparisons of all six models are described in Subsection IIIF. 


\section{A. Conversion from local standard time to local solar time}

Using Eqs. (19)-(21), the local standard times over which hourly global solar radiation data were recorded were converted to local solar times. For recommended average days of each month, the difference between local solar time and local standard time was calculated.

\section{B. Measured meteorological parameters}

Using the full dataset 2001-2010, ten-year measured monthly average hourly global solar radiation and temperature were computed from hourly data. Each month of the monthly average hourly global solar radiation was composed of 12 data points from $6 \mathrm{~h}-17 \mathrm{~h}$ local standard time. The average of the monthly average hourly global solar radiation for each hour was calculated, thus giving an average monthly value for every hour of an average year, or in other words, the average hourly global solar radiation in an average year. Each month of the monthly average hourly temperature comprised 24 data points for the 24 daily hours. A similar procedure was followed to calculate an average monthly value of temperature for every hour of an average year. With regard to temperature, monthly average daily temperature was also computed from the monthly average hourly temperature. Local standard time was converted to local solar time.

\section{Monthly average hourly radiation for the five theoretical models}

Using Eqs. (1)-(15), monthly average hourly radiation ratios were calculated at the midpoint of the solar time hourly intervals of the measured monthly average hourly global solar radiation for each of the five theoretical models WLJ, CPR, CPRG, N, and J. From the validation dataset 2006-2010, twelve measured monthly average daily global solar radiation values were computed for each of the following periods: five-year period 2006-2010 and yearly periods - 2006, 2007, 2008, 2009, and 2010. Using Eq. (16), monthly average hourly global solar radiation was calculated for each of the validation periods mentioned.

\section{Correlations between five-year monthly average hourly global solar radiation and corresponding monthly average hourly normalized temperature}

Using the calibration dataset 2001-2005, five-year measured monthly average hourly global solar radiation and its corresponding normalized temperature were computed from hourly data. The normalized temperature was calculated by normalizing monthly average hourly temperatures to their corresponding monthly average daily $(24 \mathrm{~h})$ temperature. A typical day in a month was divided into morning and afternoon periods with respect to the monthly average hourly global solar radiation. In local standard time, the morning period was from $6 \mathrm{~h}$ to $11 \mathrm{~h}$ and the afternoon period was from $12 \mathrm{~h}$ to $17 \mathrm{~h}$. For each month in the morning period, the measured monthly average hourly global solar radiation from $6 \mathrm{~h}$ to $11 \mathrm{~h}$ was regressed, in turn, against measured monthly average hourly normalized temperature from $6 \mathrm{~h}$ to $11 \mathrm{~h}, 7 \mathrm{~h}$ to $12 \mathrm{~h}, 8 \mathrm{~h}$ to $13 \mathrm{~h}$, and so on, and the respective correlation coefficients were calculated. Averages of the monthly correlation coefficients for each regression were calculated, and the value closest to 1 was selected as the best regression result. A similar procedure was repeated for each month of the afternoon period.

The normalization procedure, i.e., monthly average hourly temperature divided by monthly average daily temperature, was done since it is a process that serves to "deseasonalize" or reduce the diurnal cycle of temperature to a more "linear" relationship. The separation into morning and afternoon periods additionally reduced the complication of the diurnal temperature cycle to effect improved correlation between monthly average hourly global solar radiation and normalized temperature than is achievable without separation. Furthermore, conversion of local standard time to local solar time was not necessary since both the monthly average hourly global solar radiation and normalized temperature would experience the same time correction upon conversion which has no effect on the correlations between both measurands. 


\section{E. The D model}

Based on the findings in Subsection IIID, the D model was calibrated for the morning and afternoon periods of a typical day for each month, thus yielding twelve pairs of five-year monthly average hourly $\mathrm{D}$ models, each with its regression coefficients $a, b, c$, and $d$ determined.

\section{F. Evaluation and performance of the models}

Six validation periods were established from the validation dataset: a five-year period 2006-2010 and five one-year periods-2006, 2007, 2008, 2009, and 2010. The performance of the six models in these periods was assessed through calculated statistical test parameters and suitable graphs offering different perspectives.

For an average year of the five-year validation period 2006-2010, values of monthly average hourly global solar radiation were calculated using each of the six models. By comparing calculated and measured monthly average hourly global solar radiation, the four statistical test parameters for each model were determined for every month. Scatter plots and 1:1 lines of calculated versus measured monthly average hourly global solar radiation were produced for four months to show primarily the deviations of calculated values from measured values of each model and hence the performances of the six models. The closer the (measured, calculated) points to the 1:1 line, the better a model's performance. In the ideal case, (measured, calculated) points lie on their 1:1 line. Thus, the best performing models for each month of an average year were determined and are referred to as model-month matches in this paper. Finally, the performance of each model for the whole average year was assessed by determining the statistical test parameters between all its calculated and measured monthly average hourly global solar radiation values.

The five yearly validation periods were considered singly and collectively and through statistical test parameters, model-month matches and yearly performance were determined. The year 2008 was chosen to illustrate the performance of the top three performing models via graphs showing the variation of calculated and measured monthly average hourly global solar radiation with solar time (h) for every month. Using the five years collectively, overall modelmonth matches were determined and compared with those of the average year; the robustness of each model's performance against inter-annual fluctuations of global solar radiation and temperature was calculated by an equation provided; and the models best suited for application on both yearly and average year bases were determined from calculations using statistical test parameters.

\section{RESULTS AND DISCUSSION}

Subsections IV A-IVF present and discuss the results in accordance with Subsections III A-III F. Subsection IV G provides a summary.

\section{A. Conversion from local standard time to local solar time}

Table I lists recommended average days ${ }^{28,30}$ for the months of a year and calculated values, in hours, of the difference between local solar and standard times. It can be ascertained that the difference between local solar and standard times is relatively small, reaching a maximum magnitude on Feb 16th of $0.324 \mathrm{~h}$ or approximately 19.4 mins.

\section{B. Measured meteorological parameters}

Figure 1(a) shows plots of the variation of the average hourly global solar radiation and temperature with solar time (h), in an average year obtained from the full dataset 2001-2010. Over an average year, the average difference between local solar and standard times is less than $5 \mathrm{~min}$ and can be considered inconsequential.As the sun rises during the $6 \mathrm{~h}-7 \mathrm{~h}$, the rate of decrease in ambient air temperature slows and the temperature begins to rise after $7 \mathrm{~h}$. The minimum temperature $=23.9^{\circ} \mathrm{C}$ occurs at $7 \mathrm{~h}$. The maximum hourly global solar radiation of 
TABLE I. Recommended average days for months and calculated values, in hours, of the difference between local solar and standard times.

\begin{tabular}{lccc}
\hline \hline Month and day & $\left(t_{S O L}-t_{S T}\right)(\mathrm{h})$ & Month and day & $\left(t_{S O L}-t_{S T}\right)(\mathrm{h})$ \\
\hline Jan 17 & -0.2422 & Jul 17 & -0.1868 \\
Feb 16 & -0.3240 & Aug 16 & -0.1648 \\
Mar 16 & -0.2426 & Sep 15 & -0.0093 \\
Apr 15 & -0.0906 & Oct 15 & 0.1535 \\
May 15 & -0.0210 & Nov 14 & 0.1688 \\
Jun 11 & -0.0732 & Dec 10 & 0.0323 \\
\hline \hline
\end{tabular}

approximately $2.2 \mathrm{MJ} / \mathrm{m}^{2}$ occurs at $12 \mathrm{~h}$, while the maximum temperature of $30.7^{\circ} \mathrm{C}$ occurs at $14 \mathrm{~h}$. Figure 1 (b) shows the variation of monthly average daily $(24 \mathrm{~h})$ ambient temperature with month of an average year calculated from the period 2001-2010. The coolest months of the year are January, February, and December with average temperatures of $25.86^{\circ} \mathrm{C}, 25.90^{\circ} \mathrm{C}$, and $26.14^{\circ} \mathrm{C}$, respectively. These relatively low temperatures may be attributed to the primarily thick white cumulus clouds present in these months which have high albedos with respect to infra-red radiation, thus leading to cooler surface temperatures. All other months have average temperatures $>26.6^{\circ} \mathrm{C}$. The dry season occurs from January to May with average temperatures increasing to a maximum of $27.9^{\circ} \mathrm{C}$ in May. During the wet season, from June to December, the average temperature decreases from June to July, rises to a peak in September of $27.6^{\circ} \mathrm{C}$, and then decreases through to December. The peak in September is due to a period of increased sunshine and reduced rainfall known locally as "petit carême." The average temperature for the dry and wet seasons is $26.8 \pm 0.8^{\circ} \mathrm{C}$ and $27.1 \pm 0.5^{\circ} \mathrm{C}$, respectively.

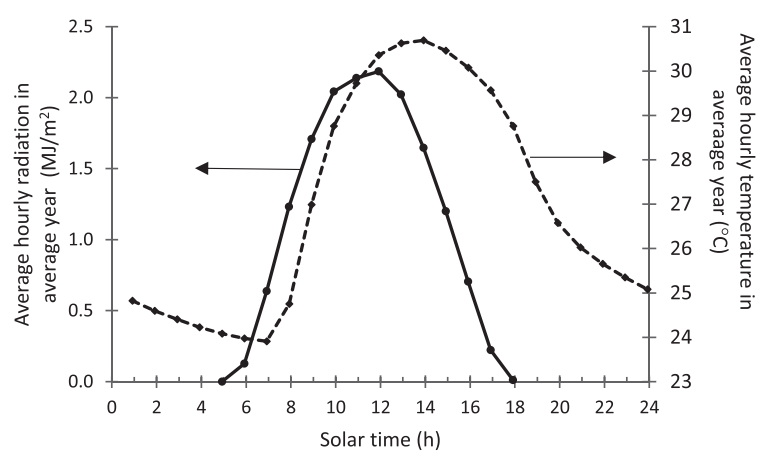

(a)

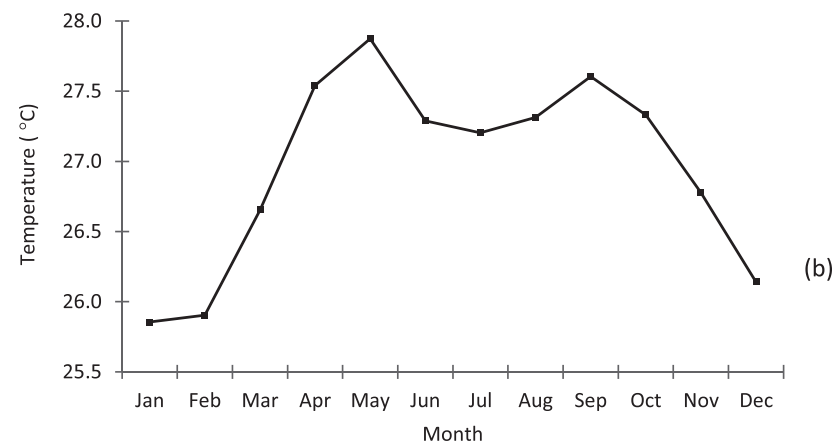

FIG. 1. (a) Variation of average hourly global solar radiation (solid line) and temperature (dashed line) in an average year with solar time (h) for the period 2001-2010. (b) Variation of monthly average daily ambient temperature with month of an average year calculated from the period 2001-2010. 


\section{Monthly average hourly radiation for the five theoretical models}

The results are deferred to Subsection IVF where calculated and measured monthly average hourly global solar radiation of all models are addressed collectively.

\section{Correlations between the five-year measured monthly average hourly global solar radiation and corresponding measured monthly average hourly normalized temperature}

Figure 2(a) is a plot of the average of the monthly correlation coefficients obtained when the measured monthly average hourly global solar radiation in the morning period $6 \mathrm{~h}-11 \mathrm{~h}$ is regressed against different measured monthly average hourly normalized temperature periods. The highest correlation, $r=0.992$, occurred when morning measured monthly average hourly global solar radiation was regressed against the measured monthly hourly normalized temperature period $7 \mathrm{~h}-12 \mathrm{~h}$. Figure 2(b) is a plot of the average of the monthly correlation coefficients obtained when the measured monthly average hourly global solar radiation in the afternoon period $12 \mathrm{~h}-17$ $\mathrm{h}$ is regressed against different measured monthly average hourly normalized temperature periods. The highest correlation, $r=0.994$, occurred when afternoon measured monthly average hourly global solar radiation was regressed against the measured monthly average hourly normalized temperature period $15 \mathrm{~h}-20 \mathrm{~h}$.

\section{E. The D model}

From the results of Subsection III D, the monthly average hourly D model for a typical day of any month is given by a pair of linear equations $\bar{H}_{m}=a \bar{T}_{m+1}-b$ and $\bar{H}_{p}=c \bar{T}_{p+3}-d$ which were previously introduced in Subsection IIF, Eqs. (17) and (18), where the variables were defined.
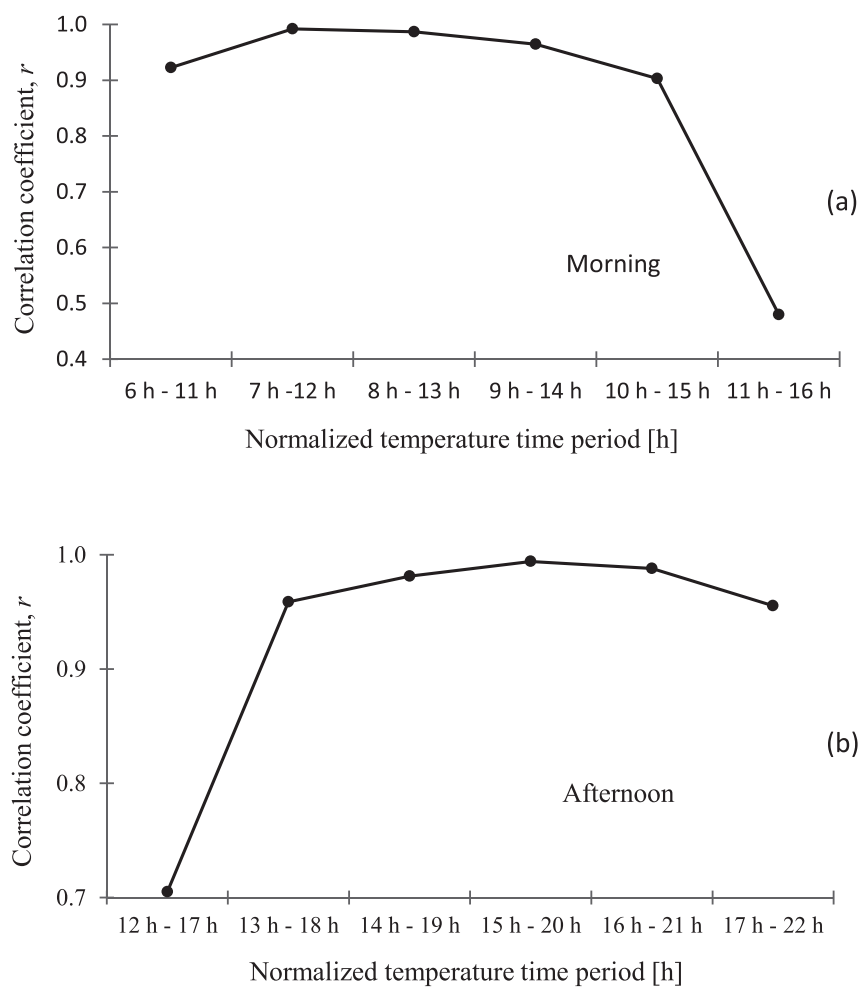

FIG. 2. (a) Plot of the average monthly correlation coefficient of the monthly average hourly global solar radiation in the morning period $6 \mathrm{~h}-11 \mathrm{~h}$ regressed against different monthly average hourly normalized temperature periods. (b) Plot of the average monthly correlation coefficient of the monthly average hourly global solar radiation in the afternoon period 12 $\mathrm{h}-17 \mathrm{~h}$ regressed against different monthly average hourly normalized temperature periods. 
Table II shows the regression coefficients $a, b, c$, and $d$ for the twelve pairs of monthly average hourly models. Coefficients $a, b, c$, and $d$ ranged from 7.26 to $10.02,6.09$ to 8.89, 11.96 to 15.25 , and 11.67 to 14.81 , respectively.

\section{F. Evaluation and performance of the models}

The models are evaluated in (i) an average year and (ii) the five yearly validation periods-singly and collectively.

The criterion for selection of the best performing models based on statistical test parameters is as follows: provided that all calculated statistical test parameters are acceptable, the model with the lowest value of RMSE is the best performing model.

\section{An average year}

Validation period 2006-2010 is a very important period of analysis. Examining this period allows an assessment of the models' performances, on average, over the longer term. It measures model performance over an average year. Fluctuations in global solar radiation and temperature can and do occur from one year to the next due to temporal variations in weather and meteorological conditions in a region. Measured monthly average hourly global solar radiation and temperature calculated from a five-year period are a more accurate representation of typical values expected over an average year in the long term, relative to a single year period. Such information allows for initial planning and design modeling of solar energy conversion systems.

Calculated statistical test parameters from all six models for a typical day of every month revealed that over the twelve months of the average year, $M B E$ ranged from -0.0577 to $0.0575 \mathrm{MJ} \mathrm{m}^{-2} \mathrm{~h}^{-1}$, RMSE ranged from 0.053 to $0.250 \mathrm{MJ} \mathrm{m}^{-2} \mathrm{~h}^{-1}, r$ ranged from 0.958 to 0.998 , and NSE ranged from 0.867 to 0.995 . For calculated statistical test parameters from all six models over an entire average year, $M B E$ ranged from -0.0398 to $0.0005 \mathrm{MJ} \mathrm{m}^{-2} \mathrm{~h}^{-1}$, $R M S E$ ranged from 0.10 to $0.18 \mathrm{MJ} \mathrm{m}^{-2} \mathrm{~h}^{-1}, r$ ranged from 0.98 to 0.99 , and NSE ranged from 0.94 to 0.98 . Thus, all statistical test parameters are acceptable on monthly bases and over an average year and hence all the models are valid in Trinidad.

Table III lists the RMSE values for the six models applied to a typical day of the months January to December and to an average year and the corresponding best performing models. The CPRG model has been chosen over the CPR model because even though both models have identical values of RMSE to two decimal places, the CPRG model had lower values of $M B E$. Where two models are listed, e.g., in March, the values of RMSE are identical to two decimal

TABLE II. Regression coefficients $a, b, c$, and $d$ for the twelve monthly average hourly D models using calibration datasets from the period 2001-2005.

\begin{tabular}{lcccc}
\hline \hline Month & $a$ & $b$ & $c$ & $d$ \\
\hline Jan & 7.42 & 6.28 & 12.53 & 12.17 \\
Feb & 7.43 & 6.15 & 12.37 & 12.00 \\
Mar & 7.88 & 6.53 & 12.54 & 12.09 \\
Apr & 8.22 & 6.92 & 13.17 & 12.63 \\
May & 9.84 & 8.68 & 14.28 & 13.74 \\
Jun & 10.02 & 8.89 & 15.25 & 14.81 \\
Jul & 9.18 & 8.03 & 14.76 & 14.36 \\
Aug & 8.06 & 6.90 & 14.10 & 13.74 \\
Sept & 7.26 & 6.09 & 14.00 & 13.68 \\
Oct & 7.80 & 7.66 & 15.07 & 14.74 \\
Nov & 8.04 & 6.28 & 13.34 & 13.01 \\
Dec & 7.29 & $6.09-8.89$ & 11.96 & 11.67 \\
Range & $7.26-10.02$ & & $11.96-15.25$ & $11.67-14.81$ \\
\hline \hline
\end{tabular}


places. The CPRG model is the best performing model for ten months except August and September. The D model is the best performer for March and September. The WLJ model is the best performer in August. These model-month matches would yield the most accurate estimations of monthly average hourly global solar radiation. Interestingly, the D model which is the only empirical model in the group performs well at a close second to the CPR/CPRG models for all the months with the exception of January and February where the WLJ model performs better. For the entire average year, the best performing model is the CPRG model with an RMSE of $0.10 \mathrm{MJ} \mathrm{m}^{-2} \mathrm{~h}^{-1}$ with the $\mathrm{D}$ model closely positioned with an RMSE of $0.12 \mathrm{MJ}$ $\mathrm{m}^{-2} \mathrm{~h}^{-1}$ and having the advantage of not requiring global solar radiation as an input parameter.

The performance of the models is displayed graphically in Fig. 3 for four representative months - January, May, September, and December. For clarity of model performance, models have been vertically separated by $2 \mathrm{MJ} / \mathrm{m}^{2}$. For each month, all the models performed well as evidenced by the proximity of their (calculated, measured) points to their respective 1:1 lines although some models performed better than others. For example, in January, all the models performed well but the CPR and CPRG models performed similarly and better than the other models, while the $\mathrm{N}$ model performed the worst. The CPR and CPRG models performed similarly to each other in every month, and this was observed for all twelve months. The six models also show monthly variation in their performances. For example, they showed larger overall spread of their points about their 1:1 lines and hence poorer performance in September than December. The better performance of the D model in September is also evident in the plot. All observations are supported by the RMSE values of the models in Table III.

\section{The five yearly validation periods-singly and collectively}

Considering the yearly validation periods 2006, 2007, 2008, 2009, and 2010 allows an assessment of the models' performances over the short term and their ability to cope with fluctuations in their input meteorological parameters due to variations in weather conditions from year to year. Such scenarios are important in fine-tuning the designs of solar energy conversion systems to cater for worse-case scenarios that can occur. The performance of the WLJ, CPR, CPRG, N, and J models will be affected by yearly fluctuations of one meteorological parameter, global solar radiation, which would impact (i) their input of monthly average daily global solar radiation and (ii) the measured monthly average hourly global solar radiation which would impact the statistical test parameters. On the other hand, the D model's performance will be

TABLE III. RMSE values (MJ $\mathrm{m}^{-2} \mathrm{~h}^{-1}$ ) for the six models for a typical day of the months January to December and for the average year in the period 2006-2010. The best performing models and corresponding values of RMSE are emboldened.

\begin{tabular}{lccccccc}
\hline \hline Months and year & WLJ & CPR & CPRG & N & J & D & Best model \\
\hline Jan & 0.112 & 0.054 & $\mathbf{0 . 0 5 3}$ & 0.160 & 0.127 & 0.120 & CPRG \\
Feb & 0.134 & 0.068 & $\mathbf{0 . 0 6 7}$ & 0.189 & 0.145 & 0.148 & CPRG \\
Mar & 0.116 & 0.098 & $\mathbf{0 . 0 9 9}$ & 0.167 & 0.174 & $\mathbf{0 . 0 9 8}$ & D, CPRG \\
Apr & 0.113 & 0.095 & $\mathbf{0 . 0 9 6}$ & 0.170 & 0.175 & 0.100 & CPRG \\
May & 0.129 & 0.065 & $\mathbf{0 . 0 6 4}$ & 0.197 & 0.150 & 0.129 & CPRG \\
Jun & 0.116 & 0.062 & $\mathbf{0 . 0 6 2}$ & 0.178 & 0.133 & 0.080 & CPRG \\
Jul & 0.130 & 0.066 & $\mathbf{0 . 0 6 4}$ & 0.186 & 0.136 & 0.098 & CPRG \\
Aug & $\mathbf{0 . 1 4 3}$ & 0.147 & 0.148 & 0.173 & 0.192 & 0.150 & WLJ \\
Sep & 0.192 & 0.206 & 0.207 & 0.210 & 0.250 & $\mathbf{0 . 1 5 1}$ & D \\
Oct & 0.137 & 0.092 & $\mathbf{0 . 0 9 1}$ & 0.180 & 0.140 & 0.098 & CPRG \\
Nov & 0.118 & 0.083 & $\mathbf{0 . 0 8 2}$ & 0.160 & 0.149 & 0.114 & CPRG \\
Dec & 0.109 & 0.058 & $\mathbf{0 . 0 5 6}$ & 0.152 & 0.132 & 0.108 & CPRG \\
Year & 0.131 & 0.101 & $\mathbf{0 . 1 0 1}$ & 0.177 & 0.162 & 0.118 & CPRG \\
\hline \hline
\end{tabular}



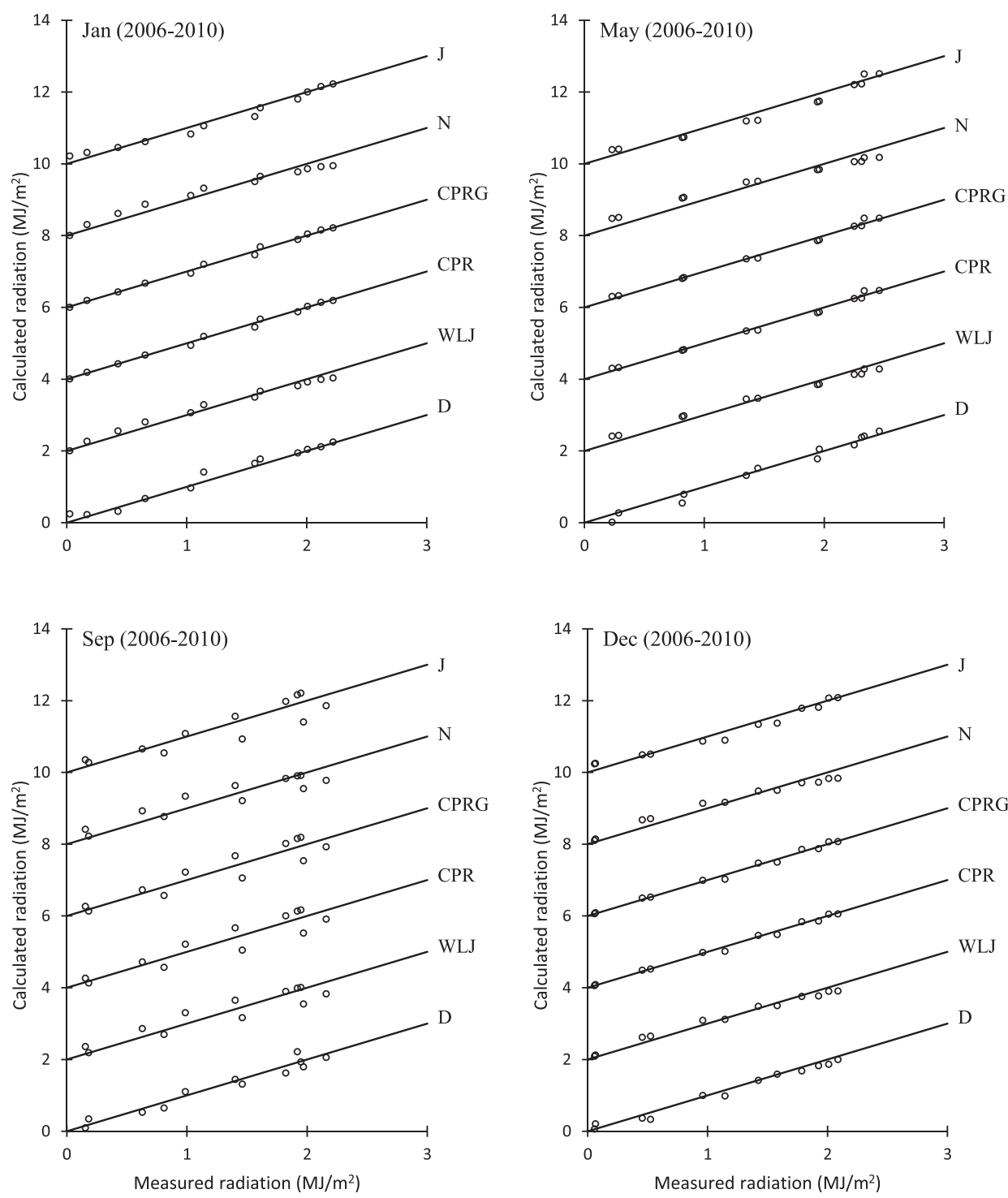

FIG. 3. 1:1 lines and plots of calculated vs measured monthly average hourly global solar radiation by six models for the months January, May, September, and December for an average year in the validation period 2006-2010. For clarity of model performance, models have been vertically separated by $2 \mathrm{MJ} / \mathrm{m}^{2}$.

affected by yearly fluctuations of two meteorological parameters: measured monthly average hourly temperature and measured monthly average hourly global solar radiation.

Considering the five years collectively allows one to determine overall model-month matches for the yearly short term, robustness of each model, and most suitable models for both yearly and average year bases.

The yearly and collective periods are examined at appropriate points in this section. The five-years collectively is designated by "2006-2010."

Table IV summarizes the ranges of the four statistical test parameters over twelve months of each year covering the six models. The ranges of the statistical parameters were acceptable for every year, thus verifying the validity of the six models for use in estimating monthly average hourly global solar radiation in yearly time frames.

Of-course, as in the case of the average year in Table III, some models would perform better than others, monthly and yearly. Table $\mathrm{V}$ lists the model-month matches for each year and "2006-2010." For "2006-2010," the average of the RMSEs for each month over the five years 
TABLE IV. Ranges of the four statistical test parameters over twelve months of each year covering the six models. $M B E$ and RMSE have units of $\mathrm{MJ} \mathrm{m}^{-2} \mathrm{~h}^{-1}$

\begin{tabular}{lcccc}
\hline \hline Validation period & MBE range & RMSE range & $r$ range & NSE range \\
\hline 2006 & $-0.0797-0.0989$ & $0.05-0.28$ & $0.922-0.997$ & $0.846-0.995$ \\
2007 & $-0.0966-0.0421$ & $0.08-0.29$ & $0.923-0.996$ & $0.800-0.991$ \\
2008 & $-0.0898-0.0567$ & $0.05-0.23$ & $0.945-0.998$ & $0.887-0.996$ \\
2009 & $-0.0906-0.0423$ & $0.05-0.36$ & $0.938-0.998$ & $0.831-0.994$ \\
2010 & $-0.0655-0.1442$ & $0.08-0.29$ & $0.893-0.994$ & $0.790-0.987$ \\
\hline \hline
\end{tabular}

TABLE V. Model-month matches for each year and the five years collectively ("2006-2010") based on the lowest RMSE. The blank spaces represent months where hourly global solar radiation data were missing.

\begin{tabular}{lcccccc}
\hline \hline Month & 2006 & 2007 & 2008 & 2009 & 2010 & “2006-2010” \\
\hline Jan & CPRG & CPRG & CPRG & CPRG & CPRG & CPRG \\
Feb & WLJ & CPRG & CPRG & CPRG & CPRG & CPRG \\
Mar & CPRG & WLJ & D & D & WLJ & D, CPRG \\
Apr & WLJ & WLJ & WLJ & D & CPRG & CPRG \\
May & CPRG & CPRG & CPRG & CPRG & CPRG & CPRG \\
Jun & CPRG & CPRG & CPRG & D & $\ldots$ & CPRG \\
Jul & D & CPRG & CPRG & CPRG & $\ldots$ & CPRG \\
Aug & CPRG & WLJ & WLJ & CPRG & D & WLJ, CPRG \\
Sep & D & D & D & WLJ & D & D \\
Oct & D & CPRG & D & CPRG & WLJ & CPRG \\
Nov & CPRG & CPRG & $\ldots$ & CPRG & D & CPRG \\
Dec & CPRG & CPRG & $\ldots$ & CPRG & CPRG & CPRG \\
\hline \hline
\end{tabular}

was calculated for each model and the best models were determined. Table VI lists the performance of all the models in terms of RMSE, yearly and collectively. For "2006-2010," the $R M S E$ is between all calculated and measured monthly average hourly global solar radiation for the five years.

From Table V, it can be found that three models, D, WLJ, and CPRG, dominated the months in all years and their re-distribution over the periods is plausible. These models had also dominated the average year in Table III. For "2006-2010," the model-month matches for the short term were similar to those for the long term in Table III except that August now included the CPRG model. There was plausible depreciation of the performance of the models in the short term compared to the average year. For example, in February, the RMSE for the CPRG model depreciated from $0.07 \mathrm{MJ} \mathrm{m}^{-2} \mathrm{~h}^{-1}$ for an average year in Table III to $0.12 \mathrm{MJ}$ $\mathrm{m}^{-2} \mathrm{~h}^{-1}$ for the short term.

TABLE VI. RMSE values (MJ $\mathrm{m}^{-2} \mathrm{~h}^{-1}$ ) of the six models for each year and the five years collectively ("2006-2010"). $R M S E$ of the best model is emboldened.

\begin{tabular}{lcccccc}
\hline \hline Period & WLJ & CPR & CPRG & N & J & D \\
\hline 2006 & 0.151 & 0.132 & $\mathbf{0 . 1 3 2}$ & 0.191 & 0.183 & 0.178 \\
2007 & 0.172 & 0.147 & $\mathbf{0 . 1 4 7}$ & 0.213 & 0.197 & 0.168 \\
2008 & 0.149 & 0.114 & $\mathbf{0 . 1 1 4}$ & 0.196 & 0.172 & 0.148 \\
2009 & 0.152 & 0.124 & $\mathbf{0 . 1 2 4}$ & 0.194 & 0.182 & 0.192 \\
2010 & 0.172 & 0.153 & $\mathbf{0 . 1 5 3}$ & 0.207 & 0.195 & 0.183 \\
"2006-2010” & 0.159 & 0.135 & $\mathbf{0 . 1 3 5}$ & 0.200 & 0.186 & 0.174 \\
\hline \hline
\end{tabular}


From Table VI, it can be found that for each year and "2006-2010," all the models performed well but the best performing model was the CPRG model which had been found to have lower values of $M B E$ than the CPR model.

The performance of the D, WLJ, and CPRG models in validation year 2008 is illustrated graphically in Fig. 4 for six months, showing how the calculated and measured monthly average hourly global solar radiation varied with solar time. The models performed well. These plots also highlight the need for caution when judging performance of models based on $M B E$, as the model with the lowest $M B E$ is not necessarily the model that best matches the measured data. For example, in March, it is clear that the D model best matches the measured radiation followed by the CPRG and WLJ models and this was supported by RMSE values of $0.13,0.15$, and $0.17 \mathrm{MJ} \mathrm{m}^{-2} \mathrm{~h}^{-1}$, respectively. However, the $M B E$ of the $\mathrm{D}$ model was the worst of the
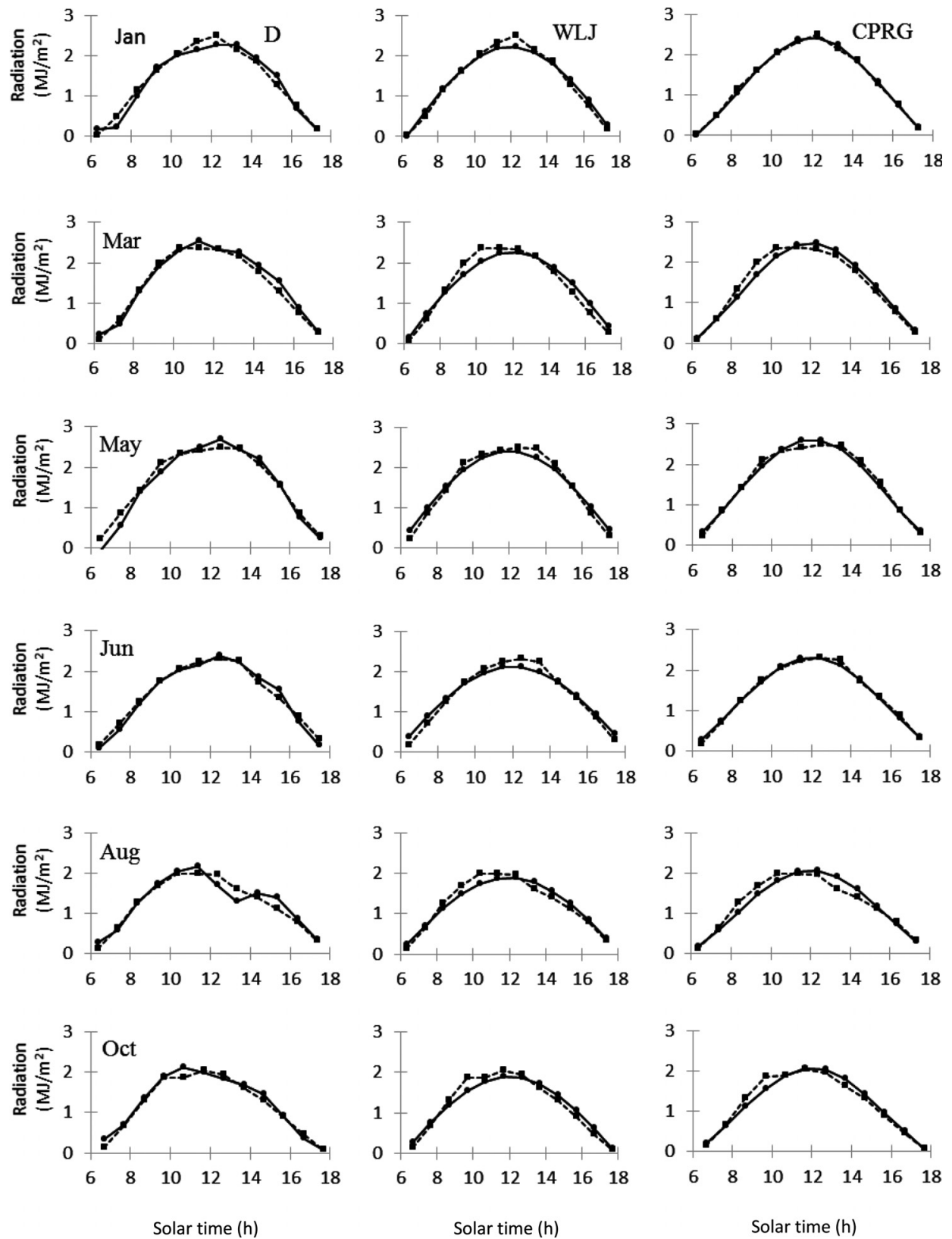

FIG. 4. Graphs of calculated (solid line) and measured (dashed line) monthly average hourly global solar radiation against solar time (h) for the D, WLJ, and CPRG models for six months of the validation period 2008. 
three at $0.0567 \mathrm{MJ} \mathrm{m}^{-2} \mathrm{~h}^{-1}$, followed by low values of 0.0007 and $0.0011 \mathrm{MJ} \mathrm{m}^{-2} \mathrm{~h}^{-1}$ for the CPRG and WLJ models, respectively. This is due to the fact that for the D model, the overestimated points are not counter-balanced by underestimated points while for the CPRG and WLJ models, overestimation is almost nullified by comparable underestimation leading to low $M B E$ values that are desirable but misleading with respect to actual model performance. This situation recurred in October. A model with the lowest $M B E$ should be judged the best model only when it simultaneously has the lowest RMSE as occurred in the months of January and June for the CPRG model.

The month of May demonstrates the sensitivity of the $\mathrm{D}$ model to the vagaries of temperature. At $6 \mathrm{~h}$, local standard time, the model given by Eq. (17) computed the hourly radiation at $-0.09 \mathrm{MJ} / \mathrm{m}^{2}$ where the measured value was $0.2 \mathrm{MJ} / \mathrm{m}^{2}$. Similar situations of negative-valued estimations also occurred at $6 \mathrm{~h}$ in May $2006\left(-0.01 \mathrm{MJ} / \mathrm{m}^{2}\right)$ and at $17 \mathrm{~h}$ in November 2010 $\left(-0.01 \mathrm{MJ} / \mathrm{m}^{2}\right)$ and December $2009\left(-0.02 \mathrm{MJ} / \mathrm{m}^{2}\right)$. This is due to the radiation at $6 \mathrm{~h}$ and $17 \mathrm{~h}$ being correlated with normalized temperatures at $7 \mathrm{~h}$ and $20 \mathrm{~h}$, respectively, which are the lowest normalized temperatures for morning and afternoon periods [see Fig. 1(a)]. Therefore, it is possible in a given year that the normalized temperatures at these times may fall to values below the typical values of an average year as obtained by averaging over a five-year period, thus leading to estimations having negative values albeit only four times in this analysis. It is important to note that the negative estimations occurred at the first and last hours of morning and afternoon periods, respectively, when global solar radiation is lower relative to hours 7 $\mathrm{h}-16 \mathrm{~h}$. For the years identified above, the actual measured radiation at the hours affected by estimated negative values as a percentage of the daily measured radiation was calculated to be $1.1 \%, 1.5 \%, 0.2 \%$, and $0.3 \%$, respectively, which would impact negligibly on designs of solar energy based systems.

The robustness, $R(\%)$, of each model toward inter-annual fluctuations in its meteorological inputs can be determined by the following equation:

$$
R(\%)=\frac{R M S E_{2}-R M S E_{1}}{R M S E_{1}} \times 100 \%,
$$

where $R M S E_{1}$ is the root mean square error for an average year contained in last row of Table III and $R M S E_{2}$ is the root mean square error for "2006-2010" contained in Table VI. The lower the value of $R(\%)$, the more robust the models are to inter-annual fluctuations in the meteorological parameters by which they are affected. Ideally, $R=0$. Table VII shows $R(\%)$ and the averages of $R M S E_{1}$ and $R M S E_{2}$ for the six models. From $R(\%)$, the most robust model is the $\mathrm{N}$ model, followed by J, WLJ, CPRG, CPR, and D models, with the latter having a value of about $48 \%$. This implies that the theoretical models are less sensitive to inter-annual fluctuations in global solar radiation than the D model is to temperature. However, the D model's higher $R(\%)$ must be considered in the context of the value of its $R M S E_{2}$, which is comparable to the WLJ, CPR, and CPRG models differing from the CPRG model by only $0.04 \mathrm{MJ} \mathrm{m}^{-2} \mathrm{~h}^{-1}$ and thus exhibiting reliable and good performance.

Finally, by considering $\left\langle R M S E_{1}, R M S E_{2}\right\rangle$, a decision can be reached as to which model or models are most appropriate to estimate monthly average hourly global solar radiation on yearly and average year bases collectively. From Table VII, it can be found that the CPRG/CPR models are the best performing models followed by the D and WLJ models. Again, as in all previous analyses, the CPRG is chosen over the CPR model by its consistently lower observed $M B E$

TABLE VII. $R(\%)$ and averages of $R M S E_{1}$ and $R M S E_{2}\left(\mathrm{MJ} \mathrm{m}^{-2} \mathrm{~h}^{-1}\right)$.

\begin{tabular}{lcccccc}
\hline \hline Parameter & WLJ & CPR & CPRG & N & J & D \\
\hline$R(\%)$ & 21.84 & 34.10 & 34.09 & 12.76 & 14.80 & 48.44 \\
$\left\langle R M S E_{1}, R M S E_{2}\right\rangle$ & 0.15 & 0.12 & 0.12 & 0.19 & 0.17 & 0.15 \\
\hline \hline
\end{tabular}


values. Both the CPRG and D models are recommended, having values of $\left\langle R M S E_{1}\right.$ and $\left.R M S E_{2}\right\rangle=0.12$ and $0.15 \mathrm{MJ} \mathrm{m}^{-2} \mathrm{~h}^{-1}$, respectively.

\section{G. Summary}

A five-year temperature-based model, the D model, has been developed, evaluated, and used to calculate monthly average hourly global solar radiation in Trinidad with good accuracy. Five existing models, WLJ, CPR, CPRG, N, and J, were also evaluated for applicability in Trinidad and found to perform well. For an average year, twelve model-month matches were established among the D, WLJ, and CPRG models. For use over an average year, the CPRG and $\mathrm{D}$ models were close in performance with the former having a lower value of RMSE by $0.02 \mathrm{MJ} \mathrm{m}^{-2} \mathrm{~h}^{-1}$. Evaluated in yearly periods resulted in a re-distribution of model-month matches of the same models, but on average, the model-month matches were in good agreement with those for an average year. Suitable models for use on yearly and average year bases were the D and CPRG models.

To determine monthly average hourly global solar radiation, the WLJ and CPRG models require measured monthly average daily global solar radiation data while the $\mathrm{D}$ model requires measured monthly average hourly temperature data. In this regard, (i) all three models can be used to fill missing monthly average hourly data provided that the requisite input data are available; (ii) when hourly temperature is more readily available at meteorological stations, then where periods of historical global solar radiation data are unavailable, the D model can be used to fill missing data; (iii) for ensuing years for the prediction of solar resources by use of temperature, the D model is favored over the WLJ and CPRG models by reason of economic considerations where the costs associated with equipment acquisition and/or maintenance and calibration are significantly lower for a temperature-based than a solar radiation-based measurement system.

\section{CONCLUSION}

Many solar energy applications require monthly average hourly global solar radiation data for optimal system design. It is therefore of paramount importance that models to predict global solar radiation on an hourly time scale be developed for use in solar energy applications. In Trinidad, data for hourly temperature are readily available from the Trinidad and Tobago Meteorological Services. A new empirical model based on monthly average hourly normalized temperature for determining monthly average hourly global solar radiation on a horizontal surface was developed and validated using calibration and validation datasets of hourly global solar radiation and temperature from 2001 to 2005 and 2006 to 2010, respectively. Five existing theoretical hourly global solar radiation ratio models developed by Whillier/Liu and Jordan, Collares-Pereira and Rabl, Gueymard, Newell, and Jain were also evaluated. These required monthly average daily global solar radiation to calculate monthly average hourly global solar radiation. Evaluation of all six models was based on statistical test parameters MBE, RMSE, $r$, and NSE. The statistical analysis confirmed that all models are valid in Trinidad but four models dominated in terms of performance during the months. For an average year determined from the five-year validation period, the temperature-based model was the best performing model for two months (March and September); the Whillier/Liu and Jordan model performed the best for one month (August); and the Collares-Pereira and Rabl and Gueymard models with virtually identical performances were the best performing models for ten months (January, February, March, April, May, June, July, October, November, and December). In an average year, the temperature-based and Gueymard models performed well with values of RMSE of 0.12 and $0.10 \mathrm{MJ} \mathrm{m}^{-2} \mathrm{~h}^{-1}$, respectively. The models were also evaluated over single years from 2006 to 2010. Some re-distribution of the same four models occurred among the months over the years, but on average, they were in agreement with those obtained for an average year. For modeling on both yearly and average year bases, the temperature-based and Gueymard models were most suitable with values of RMSE of 0.15 and $0.12 \mathrm{MJ} \mathrm{m}^{-2} \mathrm{~h}^{-1}$, respectively. Its independence of global solar radiation as an input and its comparable performance with the 
more complicated models make the temperature-based model ideally suited for use in Trinidad and for deployment in other territories with similar climates, particularly where no global solar radiation data are available.

\section{ACKNOWLEDGMENTS}

The author recognizes the invaluable contribution of the Trinidad and Tobago Meteorological Services for providing the data used in this study and the support at the Center for Optoelectronics Research.

${ }^{1}$ K. De Souza and R. Andrews, J. Renewable Sustainable Energy 7, 013132 (2015).

${ }^{2}$ T. Markvart, A. Fragaki, and J. N. Ross, Sol. Energy 80, 46 (2006).

${ }^{3}$ T. Catalina, J. Virgone, and E. Blanco, Energy Build. 40, 1825 (2008).

${ }^{4}$ M. La Gennusa, A. Nucara, M. Pietrafesa, and G. Rizzo, Sol. Energy 81, 594 (2007).

${ }^{5}$ L. Martin, L. F. Zarzalejo, J. Polo, A. Navarro, R. Marchante, and M. Cony, Sol. Energy 84, 1772 (2010).

${ }^{6}$ R. De Jong and D. W. Stewart, Can. J. Plant Sci. 73, 509 (1993).

${ }^{7}$ Y. Yunhe, W. Shaohong, Z. Du, and Y. Qinye, Agric. Water Manage. 95, 77 (2008).

${ }^{8}$ W. Zhou, C. Lou, Z. Li, L. Lu, and H. Yang, Appl. Energy 87, 380 (2010).

${ }^{9}$ A. Whillier, Arch. Meteorol. Geophys. Bioclimatol. 7, 197 (1956).

${ }^{10}$ B. Y. H. Liu and R. C. Jordan, Sol. Energy 4, 1 (1960).

${ }^{11}$ M. Collares-Pereira and A. Rabl, Sol. Energy 22, 155 (1979).

${ }^{12}$ C. Gueymard, J. Sol. Energy Eng., Trans. ASME 108, 320 (1986).

${ }^{13}$ T. A. Newell, Sol. Energy 31, 339 (1983).

${ }^{14}$ J. C. Jain, Sol. Wind Technol. 1, 123 (1984).

${ }^{15}$ K. Spokas and F. Forcella, Weed Sci. 54, 182 (2006).

${ }^{16} \mathrm{~T}$. Khatib and W. Elmenreich, Int. J. Photoenergy 2015, 1 (2015).

${ }^{17}$ D. F. Al Riza, S. I. ul Haq Gilani, and M. S. Aris, Int. J. Environ. Sci. Develop. 2, 188 (2011).

${ }^{18}$ P. G. Nikhil and D. Subhakar, Int. J. Sustainable Energy 34, 340 (2015).

${ }^{19}$ S. K. Chandel and R. K. Aggarwal, Smart Grid Renewable Energy 2, 45 (2011).

${ }^{20}$ S. Janjai, P. Pankaew, and J. Laksanaboonsong, Appl. Energy 86, 1450 (2009).

${ }^{21}$ G. H. Hargreaves and Z. A. Samani, J. Irrigation Drain Eng., ASCE 108, 223 (1982).

${ }^{22}$ K. I. Bristow and G. S. Campbell, Agric. Forest Meteorol. 31, 159 (1984).

${ }^{23}$ J. G. Annandale, N. Z. Jovanic, N. Benade, and R. G. Allen, Irrigation Sci. 21, 57 (2002).

${ }^{24}$ R. G. Allen, J. Hydrol. Eng. 2, 56 (1997).

${ }^{25}$ D. G. Goodin, J. M. S. Hutchinson, R. L. Vanderlip, and M. C. Knapp, J. Agron. 91, 845 (1999).

${ }^{26}$ Z. Sen, Sol. Energy 63, 39 (1998).

${ }^{27}$ P. I. Cooper, Sol. Energy 12, 333 (1969).

${ }^{28}$ J. A. Duffie and W. A. Beckman, Solar Engineering of Thermal Processes (John Wiley \& Sons, New York, 2013).

${ }^{29}$ J. W. Spencer, "Fourier series representation of the position of the sun," Search 2, 172 (1971).

${ }^{30}$ S. A. Klein, Sol. Energy 19, 325 (1977). 